\title{
PENGARUH PEMBERIAN VERMIKOMPOS CAIR Lumbricus rubellus Hoffmeister PADA PERTUMBUHAN Chlorella sp.
}

\section{THE RESEARCH ON THE EFFECT GIVING LIQUID VERMIKOMPOST Lumbricus rubellus ON THE GROWTH OF Chlorella sp.}

\author{
Regista $^{1}$, Ambeng $^{2}$, Magdalena Litaay ${ }^{2}$, Muh.Ruslan Umar $^{2}$ \\ ${ }^{1}$ Blue Forest Foundation Indonesia \\ ${ }^{2}$ Jurusan Biologi, Fakultas MIPA, Universitas Hasanuddin, Makassar, 90245, Indonesia \\ Email: rheqsta_90@yahoo.co.id
}

\begin{abstract}
Abstrak
Telah dilakukan penelitian tentang pengaruh pemberian vermikompos cair Lumbricus rubellus pada pertumbuhan Chlorella sp.. Penelitian ini bertujuan untuk mengetahui konsentrasi media kultur vermikompos yang terbaik dalam meningkatkan pertumbuhan populasi Chlorella sp.. Penelitian dilaksanaan di Balai Budidaya Air Payau Takalar. Jenis penelitian ini adalah eksperimen menggunakan desain percobaan Rancangan Acak Lengkap, dengan konsentrasi larutan vermikompos cair A 0\%, B 0,3\%, C 0,6\%, $D \quad 0,9 \%$, dan $E$ 1,2\%, masing-masing perlakuan 3 kali ulangan. Pengamatan pertumbuhan Chlorella sp. dilakukan selama 10 hari. Hasil analisis data menggunakan UNIANOVA diperoleh hasil yang tidak berbeda nyata antar perlakuan. Hasil penelitian menunjukkan kepadatan tertinggi populasi Chlorella sp. terjadi pada hari kesembilan dengan kepadatan $1698,91 \times 10^{4} \mathrm{sel} / \mathrm{ml}$ terjadi pada konsentrasi vermikompos cair 0,9\%.
\end{abstract}

Kata Kunci: Chorella sp., budidaya perairan, vermikompos, Chlorellaceae

\begin{abstract}
The research on the effect giving liquid vermikompost Lumbricus rubellus on the growth of Chlorella sp.The purpose of this study was to determine the best concentration of vermikompos that can increase the growth population of Chlorella sp. This researchis implemented in Brackish Water Aquaculture Center Takalar. The kind of research experimental design of experiment used Completely Randomized Design, with concentrateion vermikompos $A 0 \%, B 0.3 \%, C 0.6 \%, D 0.9 \%$, and $E 1.2 \%$, each treatment three replications. Observation of the growth of Chlorella sp. performed for 10 days. The results ofthe data analysisusing UNIANOVA and test results obtained were not significantly different between treatments. From the survey results revealed that the highest population density of Chlorella sp. occurredon day nine with $1698,91 \times 10^{4}$ density of cells $/ \mathrm{ml}$ occurred in $0.9 \%$ concentration of liquid vermikompost.
\end{abstract}

Key words: Chlorella sp., aquaculture, vermicompost, Chlorellaceae 


\section{Pendahuluan}

Mikroalga adalah sejenis tumbuhan air tingkat rendah yang berukuran renik (yang tidak dapat dibedakan akar, batang dan daunnya). Saat ini mikroalga khususnya Chlorella sp. telah banyak digunakan terutama sebagai pakan alami dalam pembenihan ikan, udang dan kerang karena memiliki kandungan nutrisi yang tinggi.Nakayama (1992) melaporkan bahwa di negara maju penggunaan Chlorella sp. sudah sangat baik dan telah menjadi makanan yang "familiar" bagi masyarakat. Chlorella sp. telah digunakan sebagai 'food additives", "taste presparatives", dan obatobatan. Agar Chlorella sp. tersedia dalam jumlah yang cukup, dapat dimanfaatkan secara massal dan berkelanjutan maka perlu dilakukan pembudidayaan.

Pembudidayaan Chlorella sp. dapat dilakukan dengan teknik akuakultur, dalam pertumbuhannya Chlorella sp. sangat dipengaruhi oleh beberapa faktor salah satunya adalah unsur hara dalam media kultur. Pada umumnya Chlorella sp. membutuhkan unsur makro $\mathrm{N}$ dan $\mathrm{P}$ dan berbagai unsur lainnya untuk meningkatkan laju pertumbuhan. Dalam budidaya Chlorella $s p$. digunakan beberapa jenis media kultur diantaranya media Walne, Guillard's $\mathrm{f} / 2$ dan Erdscheiber (Chilmawati, 2008), yang umumnya berupa media anorganik, sehingga dalam penyediaannya diperlukan biaya yang besar.

Vermikompos merupakan salah satu sumber media organik yang dapat digunakan dalam kultur Chlorella sp.. Vermikompos adalah kompos yang diperoleh dari hasil perombakan bahan-bahan organik yang dilakukan oleh cacing tanah (detrivor) sehingga dapat mengurangi jumlah sampah organik. Cacing tanah memanfaatkan sampah organik untuk metabolismenya yang menghasilkan vermikompos yang mengandung berbagai unsur hara. Unsur hara yang terkandung dalam vermikompos inilah yang dapat dimanfaatkan dalam pertumbuhan Chlorella sp. karena banyak mengandung $\mathrm{N}, \mathrm{P}$, dan $\mathrm{K}$ dsb (Mashur, 2001).

Untuk mendapatkan persediaan kultur Chlorella sp., maka diperlukan suatu studi tentang penggunaan media kultur yang dapat memberikan hasil terbaik terutama dari segi kuantitas dan kualitas Chlorella sp. yang dihasilkan. Mengingat saat ini banyak media kultur yang umumnya berbahan anorganik, dan setiap media mempunyai komposisi unsur hara yang berbeda-beda antara satu media dengan yang lain, dan masing-masing unsur hara tersebut juga mempunyai fungsi yang berbeda pula bagi Chlorella sp. yang akan dibudidayakan.Oleh Karena itudilakukan penelitian dengan tujuan untuk mengetahui konsentrasi media kultur vermikompos yang terbaik dalam meningkatkan pertumbuhan populasi Chlorella sp.

\section{Bahan dan Metode}

\section{Bahan}

Bahan yang digunakan pada penelitian ini meliputi algae uniseluler Chlorella sp, pupuk vermikompos, pupuk Walne, Air Laut steril, sedangkan alat yang digunakan meliputi erlenmeyer, counting chamber, rak kultur dan mikroskop.

\section{Desain dan Analisis Penelitian}

Penelitian ini bersifat eksperimental, dengan menggunakan desain penelitian Rancangan Acak Lengkap (RAL) yang terdiri dari 5 perlakuan dengan konsentrasi vermikompos yang berbeda yaitu perlakuan A : 0 ml-I, B : $30 \mathrm{ml}$, C : $60 \mathrm{ml}$-, D : $90 \mathrm{ml}$, dan $\mathrm{E}: 120 \mathrm{ml}$, dan masing-masing perlakuan di ulang 3 kali. Persamaan umum Rancangan Acak Lengkap (Gaspersz, 1991):

$$
Y_{i j}=\mu_{j}+T_{i}+\epsilon_{i j} \text {, }
$$


Diketahui :

$\mu=$ nilai tengah populasi,

$\mathrm{Ti}$ = pengaruh aditif dari perlakuan ke-i,

$\epsilon i j$ = galat percobaan dari ke-i pada pengamatan ke-j.

Data hasil penelitian di analisis dengan uji sidik ragam ANOVA satu faktor, dan jika terdapat perbedaan nyata antar perlakuan maka akan dilanjutkan uji sederhana dengan Uji Jarak Berganda Duncan (HSD). Persamaan umum Uji Jarak Berganda Duncan (Gaspersz, 1991) :

Diketahui :

$$
S_{Y}=\left(s^{2} / r\right)^{1 / 2} \text {, }
$$

$\mathrm{s}^{2}=$ nilai kuadrat tengah galat,

$r=$ jumlah ulangan.

\section{Penyiapan Kultur Chlorella sp.}

Sebelum perlakuan terlebih dahulu dilakukan perbanyakan sel Chlorella sp.. Sel yang diperbanyak berasal dari stok biakan murni. Kepadatan awal Chlorella sp.yang digunakan adalah 100.000 $\mathrm{sel} / \mathrm{ml}$. Untuk menghitung besarnya inokulum yang dibutuhkan digunakan rumus (Fox, 1983):

Diketahui :

$$
V_{r}=V_{c} \times C_{f} / C_{c}
$$

$\mathrm{V}_{\mathrm{r}}=$ volume inokulum yang dibutuhkan $(\mathrm{ml}), \mathrm{V}_{\mathrm{c}}=$ volume air media kultur $(1000 \mathrm{ml})$,

$\mathrm{C}_{F}=$ kepadatan awal yang dibutuhkan $(100000 \mathrm{sel} / \mathrm{ml})$,

$\mathrm{C}_{\mathrm{c}}=$ kepadatan sel inokulum (sel/ml).

Sebanyak 5 buah erlenmeyer yang berisi media air laut dengan volume yang berbeda-beda dan salinitas $30 \%$ diletakkanpada rak kultur yang dilengkapi dengan aerasi dan 2 lampu neon $40 \mathrm{TL}$. Kemudian dimasukkan vermikompos dengan konsentrasinya masing-masing ke dalam media air laut tersebut, dan Chlorella sp. dikultur selama 10 hari pada suhu $25^{\circ} \mathrm{C}$.

Perlakuan I dengan konsentrasi vermikompos $0 \%$ sebagai kontrol tetapi diberi pupuk walne sebanyak $1 \mathrm{ml}$ dengan volume air laut $1000 \mathrm{ml}$. Perlakuan II konsentrasi vermikompos $0.3 \%$ dengan volume air laut $970 \mathrm{ml}$. Perlakuan III konsentrasi vermikompos $0.6 \%$ dengan volume air laut $940 \mathrm{ml}$. Perlakuan IV konsentrasi vermikompos 0.9\% dengan volume air laut $910 \mathrm{ml}$. Perlakuan V konsentrasi vermikompos $1.2 \%$ dengan volume air laut $880 \mathrm{ml}$. Selanjutnya dimasukkan Chlorella sp. dengan kepadatan $100.000 \mathrm{sel} / \mathrm{ml}$ ke dalam masing-masing Erlenmeyer. Chlorella sp. dikultur selama 10 hari dengan penyinaran selama 24 jam dan diaerasi terusmenerus.

\section{Perhitungan Kepadatan Chlorella sp.}

Kepadatan populasi Chlorella sp. dihitung jumlah populasi sel setiap 24 jam sekali, yang dimulai dari hari pertama sampai hari kesepuluh. Jumlah sel dihitung dengan menggunakan haemocytometer yang diletakkan di bawah lensa objektif mikroskop dengan pembesaran 10 kali. Penentuan jumlah Chlorella sp. diketahui dengan cara menghitung banyaknya jumlah Chlorella sp. yang terdapat dalam 4 kotak besar yang berukuran sisi 1 milimeter pada hemasitometer, dalam perhitungan jumlah sel juga di gunakan handcounter. Kerapatan sel dalam $1 \mathrm{ml}$ sampel dihitung dengan rumus (Prihantini, 2005):

Diketahui :

$$
k=n \times p \times 2500 \text {, }
$$

$\mathrm{k}=$ kerapatan sel Chlorella sp. (sel/ml),

$\mathrm{n}=$ jumlah total sel Chlorella sp. pada keempat kotak kamar hitung,

$p=$ tingkat pengenceran yang digunakan. 


\section{Pengolahan dan Analisis data}

Laju pertumbuhan (k) Chlorella sp. di hitung dengan rumus persamaan menurut Hirata, 1981, sebagai berikut :

Diketahui :

$$
k=\frac{\log \left(\frac{N t}{N o}\right)}{T t-T o} x 3.22,
$$

$\mathrm{Nt}=$ kepadatan populasi padawaktu t,

$\mathrm{No}=$ kepadatanpopulasi sel pada waktu $\mathrm{O}$,

$3,22=$ nilai konstanta,

To $=$ waktu awal,

$\mathrm{Tt}=$ waktu pengamatan

Data hasil penelitian kemudian ditabulasi untuk selanjutnya diolah dengan menggu-nakan program analisis statistik (Software) SPSS ver. 17, hasil dari pengolahan data kemudian disajikan dalam bentuk tabel dan di interpretasikan.

\section{Pertumbuhan Chlorella sp}

\section{Hasil}

Hasil pengamatan terhadap pertumbuhan Chlorella sp. selama penelitian menggunakan pupuk vermikompos cair dengan konsentrasi berbeda yaitu $0 \%, 0,3 \%, 0,6 \%, 0,9 \%$ dan $1,2 \%$ selama 10 hari masing-masing dengan 3 kali ulangan disajikan pada Tabel 1 dan Gambar 1.

Tabel 1. Kepadatan rata-rata Chlorella sp. (x 104 sel/ml)

\begin{tabular}{|c|c|c|c|c|c|}
\hline \multirow[t]{2}{*}{ Harike- } & \multicolumn{5}{|c|}{ Konsentrasi Vermikompos Cair (\%) } \\
\hline & 0 & 0,3 & 0,6 & 0,9 & 1,2 \\
\hline 1 & 10 & 10 & 10 & 10 & 10 \\
\hline 2 & 53.75 & 21.50 & 20.50 & 19.08 & 20.83 \\
\hline 3 & 56.33 & 56.50 & 66.58 & 65 & 53.08 \\
\hline 4 & 95.83 & 212.83 & 163 & 155.33 & 137 \\
\hline 5 & 316.33 & 322 & 510.75 & 491.33 & 489 \\
\hline 6 & 929.25 & 777.33 & 1398.75 & 1332.50 & 1243.75 \\
\hline 7 & 952.83 & 568.08 & 1281.25 & 1222.50 & 1372.91 \\
\hline 8 & 1050 & 822.50 & 1053.75 & 1291.25 & 1427.50 \\
\hline 9 & 1322.5 & 1182.75 & 1512 & 1698.92 & 1395 \\
\hline 10 & 1238.75 & 1017 & 1447.50 & 1347.50 & 1544.17 \\
\hline Total & 6025.57 & 4990.49 & 7464.08 & 7633.41 & 7693.24 \\
\hline Rata-Rata & 602.557 & 499.049 & 746.408 & 763.341 & 769.324 \\
\hline
\end{tabular}

Berdasarkan data hasil pengamatan, diketahui bahwa puncak kepadatan rata-rata tertinggi Chlorella sp. sebesar $1698.92 \times 10^{4} \mathrm{sel} / \mathrm{ml}$ terjadi di hari kesembilan pada konsentrasi verimkompos cair $0.9 \%$. Rata-rata tiap perlakuan mengalami puncak kepadatan pada hari kesembilan kecuali pada perlakuan $1.2 \%$ vermikompos cair yang mencapai puncak kepadatan pada hari kesepuluh.

Hasil analisis sidik ragam UNIANOVA (Univariate Analysis of Variaence) pengaruh vermikompos terhadap pertumbuhan populasi sel Chlorella sp. menunjukkan bahwa tidak ada perbedaan nyata antara perlakuan konsentrasi vermikompos cair terhadap pertumbuhan Chlorella sp. pada taraf uji 0.05. Walaupun hasil uji UNIANOVA tidak menunjukkan hasil yang berbeda nyata antara perlakuan, namun pada kenyataannya bahwa pemberian perlakuan beberapa konsentrasi vermikompos terlihat tetap mampu merangsang pertumbuhan Chlorella sp (Gambar 1). 


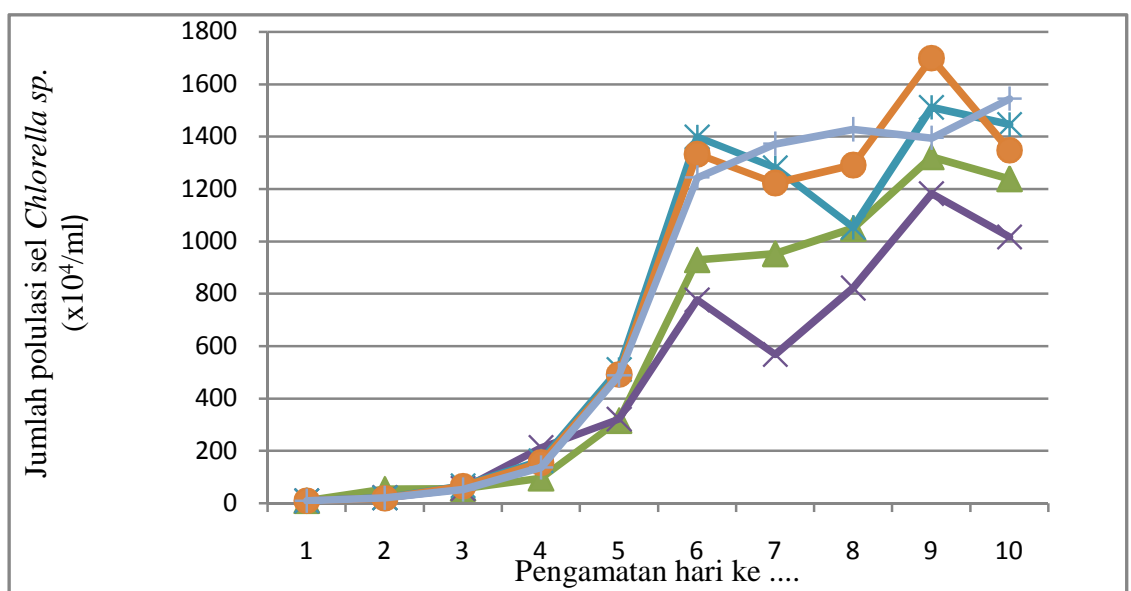

Gambar 1. Hubungan antara hari pengamatan dengan tingkat kepadatan Chlorella sp. $\left(\times 10^{4} \mathrm{sel} / \mathrm{ml}\right)$ terhadap konsentasi vermikompos.

Laju pertumbuhan suatu mikroalga adalah suatu ukuran pertambahan biomassa dalam rentang waktu tertentu dan ditentukan dari fase eksponensial. Besarnya konstanta laju partumbuhan menggambarkan tingkat kesuksesan relatif suatu mikroalga dalam beradaptasi terhadap lingkungan alaminya atau media kultur buatan (Akbar, 2008). Laju pertumbuhan Chlorella sp. selama penelitian dapat dilihat pada Gambar 2. Apabila nilai laju pertumbuhan ( $k$ ) lebih besar hal ini menunjukkan bahwa proses pembelahan Chlorella sp. menjadi lebih cepat sehingga pertambahan sel per satuan waktuakan lebih besar dari pertambahan waktu itu sendiri.

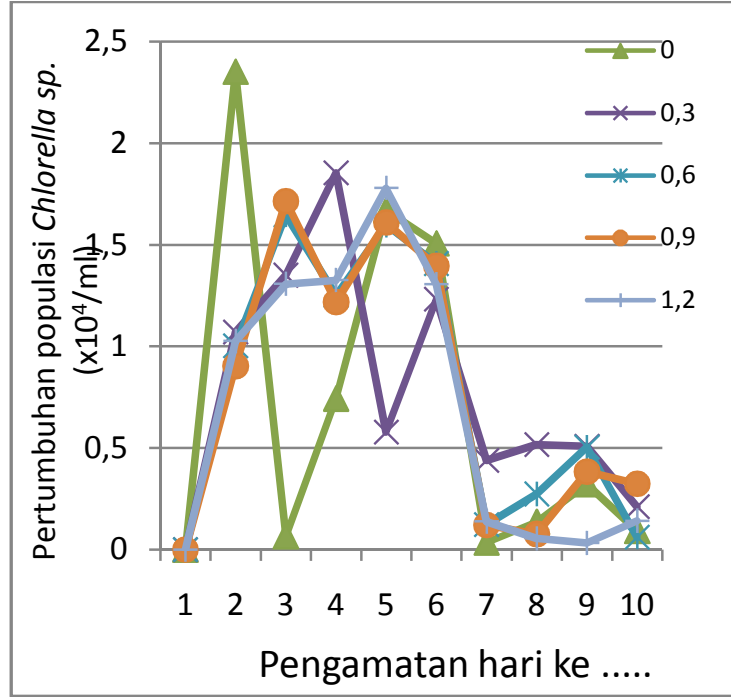

Gambar 2. Laju pertumbuhan Chlorella sp.

Berdasarkan laju pertumbuhan rata-rata yang diperoleh, menunjukkan umur kultur yang digunakan sebagai inokulum dalam tahap kultur populasi Chlorella sp. berada dalam tahap eksponensial.

Selama masa inkubasi (10 hari) terjadi perubahan warna pada seluruh media perlakuan yang semula berwarna bening kekuningan berubah menjadi hijau zamrud seperti diperlihatkan pada. Warna hijau dari kelima perlakuan media perlakuan relatif sama kecuali pada perlakuan I yang warnanya hijau kekuningan. Perubahan warna kultur tersebut diikuti dengan peningkatan kerapatan sel (Gambar 1). Peningkatan kerapatan sel Chlorella sp. pada kelima media perlakuan 
menandakan terjadinya pemanfaatan nutrien yang terkandung dalam vermikompos cair oleh selsel Chlorella sp..

\section{Pembahasan}

Vermikompos cair yang digunakan dalam penelitian ini mengandung berbagai unsur hara baik makronutrien maupun mikronutrien yang dibutuhkan bagi pertumbuhan Chlorella sp. Dickerson (2001) mengemukakan bahwa vermikompos tidak hanya berisi kotoran cacing tetapi juga bahan dan limbah organik dari hasil dekomposisi. Hal ini menyebabkan verminkompos mengandung nitrogen, fosfor, dan kalium 5- 11 kali lebih banyak dari tanah.

Pengaruh nutrien terhadap pertumbuhan Chlorella sp.ditentukan dengan laju pertumbuhan Chlorella sp. yang diketahui dari pertambahan densitas Chlorella sp. (Lavens dan Sorgeloos 1996).Lebih lanjut menurut Sen et al. (2005), bahwa nutrien atau unsur hara merupakan parameter penting yang mendukung pertumbuhan mikroalga Chlorella sp.. Unsur hara tersebut terdiri atas mikronutrien dan makronutrien. Makronutrien antara lain adalah $\mathrm{C}, \mathrm{H}, \mathrm{N}, \mathrm{P}, \mathrm{K}, \mathrm{S}, \mathrm{Mg}$, dan $\mathrm{Ca}$, sedangkan mikronutrien yang dibutuhkan adalah $\mathrm{Fe}, \mathrm{Cu}, \mathrm{Mn}, \mathrm{Zn}, \mathrm{Co}, \mathrm{Mo}, \mathrm{Bo}, \mathrm{Vn}$.

Unsur-unsur hara berperan dalam pembentukan protein dan membentuk warna hijau pada Chlorella sp. (Amini, 2004). Fosfor dan kalsium berperan dalam pembelahan sel, sehingga semakin cepat pembelahan sel terjadi semakin cepat pertumbuhan dan kepadatan sel. Magnesium berfungsi dalam pembentukkan minyak, sehingga Chlorella sp. dapat menghasilkan minyak.

Pada setiap perlakuan terlihat perbedaan dalam jumlah populasi Chlorella sp. yang dihasilkan, hal ini disebabkan karena adanya perbedaan konsentrasi vermikompos yang diberikan, dimana masing-masing konsentrasi menggandung kadar unsur hara yang berbeda. Konsentrasi vermikompos yang rendah kemungkinan mengadung unsur hara dalam jumlah sedikit pula sehingga Chlorella sp. relatif kurang bertumbuh secara optimal, begitupula jika konsentrasi vermikompos terlalu tinggi, kemungkinanya juga akan mengadung unsur hara dalam jumlah yang besar sehingga dapat mempengaruhi pertumbuhan Chlorella sp.

Kepadatan populasi Chlorella sp. pada hari kedua dan ketiga hampir sama pada semua perlakuan. Hal ini menunjukkan bahwa hari kedua dan hari ketiga merupakan fase adaptasi yaitu fase penyesuaian diri dengan media kultur yang sudah diberi pupuk/nutrien. Menurut Fogg dan Thake (1987) dalam Prihantini (2005) salah satu faktor yang menentukan lamanya fase adaptasi adalah umur kultur yangdigunakan sebagai inokulum. Fase adaptasi akan menjadi lebih singkat atau bahkan tidak terlihat apabila sel-sel yang diinokulasikan berasal dari kultur yang berada dalam fase eksponensial. Selain itu Akbar (2008) mengemukakan bahwa fase adaptasi juga ditentukan oleh medium dan lingkungan petumbuhan. Sel yang ditempatkan dalam medium dan lingkungan pertumbuhan sama seperti medium dan lingkungan sebelumnya, mungkin tidak diperlukan waktu adaptasi. Tetapi jika nutrien yang tersedia dan kondisi lingkungan yang baru sangat berbeda dengan yang sebelumnya, diperlukan waktu penyesuaian untuk mensintesis enzim-enzim yang dibutuhkan untuk metabolisme.

Perbedaan populasi mulai terlihat pada hari keempat, setelah itu populasi pada tiap perlakuan fluktuatif. Pada hari ke sembilan dan ke sepuluh pertumbuhan Chlorella sp telah memasuki fase pertumbuhan secara eksponensial yaitu terjadinya pembelahan sel yang semakin cepat akibat daya dukung lingkungan memenuhi syarat untuk pertumbuhan organisme.

Populasi Chlorella sp. yang fluktuatif pada perlakuan dapat disebabkan jumlah sel yang terlalu banyak sehingga keberadaan sel dalam media kultur sangat rapat menyebabkan banyak sel yang tidak mampu bertahan dan mengalami kematian. Banyaknya sel yang mati menyebabkan ketersedian ruang dalam media kultur menjadi renggang, dan jika nutrien yang tersedia dalam wadah kultur masih mencukupi maka pertumbuhan Chlorella sp. dapat meningkat lagi. Faktor lainnya yang dapat mempengaruhi pertumbuhan adalah intensitas cahaya yang dapat diserap 
oleh sel dalam kultur. Bila cahaya yang terserap oleh Chlorella sp. berkurang menyebabkan laju fotosintesis berjalan lambat, sehingga mengakibatkan pertumbuhan sel menurun. Hal ini sesuai dengan hasil penelitian yang dilakukan oleh Pambudi (2001) yang memperlihatkan bahwa kepadatan populasi yang cukup tinggi akan menyebabkan self shading (penutupan diri sendiri) dari Chlorella sp juga tinggi. Keadaan ini menyebabkan penetrasi cahaya yang masuk kedalam media kultur berkurang, sehingga proses fotosintesis tidak dapat berlangsung dengan normal dan menyebabkan tingkat kematian menjadi tinggi.

Menurut Fogg, 1971 dalam Sutomo (2005), perubahan kondisi lingkungan atau media kultur mikroalga seperti intensitas cahaya dan konsentrasi nutrien sel, dapat menghasilkan senyawa otoinhibitor. Pembentukan senyawa otohinbitor dapat mempersingkat pertumbuhan sel dalam kultur, sehingga pertumbuhan sel relatif menurun. Salah satu mikroalga yang menghasilkan otohinbitor adalah Chlorella sp.. Senyawa ini merupakan produk metabolisme sel yang disekresikan dan diakumulasikan ke medium yang mempunyai efek menghambat pertumbuhanmikroalga itu sendiri (Myers, 1953 dalam Sutomo,2005).

Boyd (2004) mengemukakan bahwa selain unsur hara kepadatan sel juga dipengaruhi oleh temperatur, salinitas, cahaya, dan $\mathrm{pH}$. Semua faktor tersebut harus berada dalam kondisi optimum untuk pertumbuhan mikroalga agar produk sel dan bahan metabolit berada dalam keadaan maksimum (Sutomo, 2005).

Suhu adalah salah satu faktor yang berpengaruh terhadap produktifitas mikroalga, karena setiap spesies mempunyai suhu optimalnya tersendiri. Venkatamar, 1969 dalam Sidabutar (1999) menyataan bahwa peningkatan suhu air menyebabkan peningkatan aktivitas sel sehingga metabolisme berjalan lebih cepat. Akan tetapi suhu yang tinggi menyebabkan kematian dengan cepat. Dari pengamatan suhu ruangan diperoleh hasil bahwa suhu ruangan berkisar antara 19 $25^{\circ} \mathrm{C}$, hal ini sesuai dengan yang dikemukan De La Noue dan De Paw, 1998 dalam Sutomo (2005) bahwa suhu optimal untuk pertumbuhan mikroalga berkisar $15^{\circ} \mathrm{C}$ sampai $30^{\circ} \mathrm{C}$, hal ini berarti suhu selama penelitian terletak pada kisaran suhu optimal.

Nilai $\mathrm{pH}$ media kultur merupakan faktor pengontrol yang menentukan kemampuan biologis Chlorella sp. dalammemanfaatkan unsur hara (Prabowo, 2009). pH media berpengaruh terhadap konsentrasi $\mathrm{CO}_{2}$ dan pada keseimbangan antara ion bikarbonat dan arbonat. Pengukuran tehadap $\mathrm{pH}$ media kultur menggunakan $\mathrm{pH}$ indikator diperoleh hasil bahwa $\mathrm{pH}$ media kultur berada pada kondisi netral $(\mathrm{pH}=7)$. Menurut Round, 1973 dalam Sidabutar (1999) pH optimum bagi pertumbuhan Chlorella sp. antara $7-8$.

Cahaya merupakan kebutuhan utama bagi Chlorella sp. karena mikroalga ini adalah organisme fototrof. Cahaya dibutuhkan untuk proses fotosintesis dan hasil dari fotosintesis digunakan untuk pertumbuhan Chlorella sp.. Menurut Ohama dan Miyachi (1998) proses fotosintesis dari Chlorella sp. membutuhkan intensitas cahaya antara 3000 - 30.000 lux dan intensitas cahaya yang terukur selama penelitian sebesar 3.200 lux. Nilai ini masih berada pada kisaran intensitas cahaya yang dibutuhkan oleh Chlorella sp..

Faktor lingkungan lain yang terukur adalah salinitas. Salinitas media kultur yangterukur sebesar 30 ppm. Chlorella sp. dapat tumbuh optimal pada salinitas 25-34 ppm, sementara salinitas 15 ppm tumbuh lambat dan tidak tumbuh pada salinitas 0 ppm dan 60 ppm (Rostini, 2007).

\section{Kesimpulan}

Berdasarkan hasil penelitian pertumbuhan populasi sel Chlorella sp. pada media pupuk vermikompos dapat disimpulkan bahwa konsentrasi pupuk cair vermikompos yang diperlakukan tidak berpengaruh nyata terhadap pertumbuhan populasi sel Chlorella sp. Perlakuan yang memberikan pertumbuhan populasi sel Chlorella sp. tertinggi adalah konsentrasi vermikompos cair $0,9 \%$ dengan puncak kepadatan sel rata-rata sebesar $16.989 .100 \mathrm{sel} / \mathrm{ml}$ yang terjadi pada hari ke sembilan. 


\section{Daftar Pustaka}

Akbar, T. M., 2008. Pengaruh Cahaya Terhadap Senyawa Antibakteri dari Chaetoceros gracilis. Skripsi Program Studi Teknologi Hasil Perikanan. Fakultas Perikanan dan Ilmu Kelautan. IPB. Bogor.

Boyd, J. 2004. Oceanography, Water, Seawater Ocean Circulation and Dinamics. Chemical week, June 29. Pub Ink USA.

Amini, S. 2005. Konsentrasi Unsur Hara pada Media dan Pertumbuhan Chlorella Vulgaris dengan Pupuk Organik Teknis dan Analis. Jurnal Perikanan (J.Fish Sci). Vol 8 (2): 201-206.

Chilmawati, D. dan Suminto. 2008. Penggunaan Media Kultur Yang Berbeda Terhadap Pertumbuhan Chlorella sp.: Jurnal Saintek Perikanan, Vol. 4 (1): 42 - 49.

Dickerson, G. W. 2001. Vermikomposting. New Mexico State University. USA.

Fox, J. M. 1983. Intensive Algal Culture Techniques In: Mc. Vey, J.P. and J. R. More (editor). CRC Handbook of Marine Culture Series, vol 1. Crustacean Aqua Culture. CRC Press Inc. Boca Rotan. Florida.

Gaspersz, V. 1991. Metode Perancangan Percobaan. CV. Armico. Bandung. Hal 35 dan 92.

Hirata, H. I. Andarias and S. Yamasaki. 1981. Effect of salinity temperature on the growth of the marine phytoplankton Chlorella saccharophila. Mem. Fac. Fish. Kaghosima Univ. 30: 257262.

Lavens, P dan Sorgeloos P (eds). 1996. Manual on The Production And Use Of Live Food For Aquaculture. FAO Fisheries Technical Paper. No. 361. Rome: Food 8and Agriculture Organization of the United Nations.

Mashur. 2001. Vermikompos Pupuk Organik berkualitas dan ramah Lingkungan. Instalasi Penelitian dan Pengkajian Teknologi Pertanian, Mataram.

Nakayama, R. 1992. Scientific Reports on Chlorella in Japan. Silpaque publishing, Inc. Kyoto. Japan.

O-Hama, T. dan S. Miyachi. 1998. Chlorella. Dalam : Microalgae Biotechnology Borowitzka, L. J. (ed.). Cambridge University Press. London. p: 4.

Prabowo, D. A. 2009. Optimasi Penembangan Media Untuk Pertumbuhan Chlorella sp. Pada Skala Laboratorium. Skripsi Program Studi IImu dan Teknologi Kelautan. Fakultas Perikanan dan Ilmu Kelautan. IPB. Bogor.

Pambudi, L.T. 2001. Pengaruh Sinar Merah dengan Panjang Gelombang yang Berbeda Terhadap Pertumbuhan Kultur Mumi Chlorella. Skripsi. Program Studi Budidaya Perairan. Fakultas Perikanan dan Ilmu Kelautan. IPB. Bogor.

Prihantini, N.B. 2005. Pertumbuhan Chlorella spp. Dalam Medium Ekstrak Tauge (MET) Dengan Variasi pH Awal: Makara, Sains. Vol 9 (1): 1-6.

Rostini, I. 2007. Kultur Fitoplankton (Chlorella spp. dan tetraselmis chuii) Pada Skala Laboratorium. Tesis tidak diterbitkan. FPIK Universitas Padjajaran.

Sen B, Alp MT, dan Kocer MAT. 2005. Studies on Growth Of Marine Microalgae In Batch Culture: II. Isochrysis galbana (haptophyta). Asian Journal of Plant Sciences. Vol 4(6): 639-641.

Sidabutar, E. A. 1999. Pengaruh Jenis Medium Pertumbuhan Mikroalga Chlorella sp. Terhadap Aktivitas Senyawa Pemacu Pertumbuhan Yang Dihasilkan. Skripsi. Program Studi Teknologi Hasil Perikanan. Fakultas Perikanan dan Ilmu Kelautan. IPB. Bogor.

Sutomo. 2005. Kultur Tiga Jenis Mikroalga (Tetraselmis sp., Chlorella sp. dan Chaetoceros gracilis) dan Pengaruh Kepadatan Awal Terhadap Pertumbuhan C. Gracilis di Laboratorium. Oseanologi dan limnology di Indonesia. (37): 45-58 